SILVA, Fernando Fernandes da; SARTORI, Marcelo Vanzella. A desapropriação e a proteção dos bens culturais no Direito Brasileiro. Revista Eletrônica Direito e Política, Programa de PósGraduação Stricto Sensu em Ciência Jurídica da UNIVALI, Itajaí, v.10, n.1, edição especial de 2015. Disponível em: www.univali.br/direitoepolitica - ISSN 1980-7791.

\title{
A DESAPROPRIAÇÃO E A PROTEÇÃO DOS BENS CULTURAIS NO DIREITO BRASILEIRO
}

\author{
THE EXPROPRIATION AND THE PROTECTION OF CULTURAL PROPERTY IN \\ BRAZILIAN LAW
}

Fernando Fernandes da Silva ${ }^{1}$

Marcelo Vanzella Sartori ${ }^{2}$

SUMÁRIO: Introdução; 1. O Patrimônio Cultural Brasileiro e as Medidas de Proteção; 2. A Desapropriação no Direito Brasileiro; 3. A Desapropriação como Instituto de Proteção do Patrimônio Cultural Brasileiro; 3.1. A desapropriação por utilidade pública ou interesse social; 3.2. A desapropriação pelo valor cultural; 3.2.1. A desapropriação e o tombamento prévio; 3.2.2. A desapropriação e o tombamento oneroso; 3.3. A desapropriação e a política urbana; Considerações finais; Referências das fontes citadas.

RESUMO: O nosso objetivo neste artigo é a sistematização do tema da desapropriação dos bens culturais como um dos instrumentos de tutela do patrimônio cultural brasileiro, que possibilita uma melhor compreensão da sua aplicação pela sociedade e pelo Poder Público e também, a sua análise no âmbito jurídico, em especial pelos seus aspectos constitucionais. Partimos do pressuposto de que o bem cultural é espécie de bem ambiental que pode ser tutelado pela desapropriação: a desapropriação direta, subsidiária ao tombamento ou como alternativa ao tombamento oneroso ou como instrumento de promoção da política urbana.

\footnotetext{
1 Professor de Direito Internacional Público e Privado do curso de graduação em Direito da Faculdade de Direito de Sorocaba; Professor de Direito Internacional Público e Privado do curso de graduação em Direito da Faculdade de Direito da Universidade Católica de Santos (UniSantos); Coordenador e Professor de Direito Ambiental Internacional do curso de doutorado do Programa de Mestrado e Doutorado em Direito Ambiental Internacional da UniSantos, na cidade de Santos/SP, Brasil. E-mail: ffernandes@unisantos.br

2 Doutorando em Direito Ambiental Internacional e Mestre em Direito Ambiental - UNISANTOS, na cidade de Santos/SP, Brasil; Bolsista CAPES/PDSE - Proc. n 2208/14-8; Professor Universitário (Faculdade Santa Lúcia - Mogi Mirim/SP - Brasil e Faculdade Municipal Prof. Franco Montoro - Mogi Guaçu/SP - Brasil); Advogado e Consultor Jurídico; e-mail: vanzellasartori@hotmail.com
} 
SILVA, Fernando Fernandes da; SARTORI, Marcelo Vanzella. A desapropriação e a proteção dos bens culturais no Direito Brasileiro. Revista Eletrônica Direito e Política, Programa de PósGraduação Stricto Sensu em Ciência Jurídica da UNIVALI, Itajaí, v.10, n.1, edição especial de 2015. Disponível em: www.univali.br/direitoepolitica - ISSN 1980-7791.

Palavras-chave: Desapropriação; Patrimônio Cultural; Constituição Federal; Instrumento; Tutela.

\begin{abstract}
Our goal in this article is the systematization of the subject of expropriation of cultural property as an instrument of protection of the Brazilian cultural heritage, which allows a better understanding of their application by society and the government and also, its analysis of the legal framework, especially by its constitutional aspects. We assumed that the cultural properties are kind of environmental properties that can be protected by the expropriation: direct expropriation, subsidiary to tipping or as an alternative to costly tipping or as a tool to promote urban policy.
\end{abstract}

Keywords: Expropriation; Cultural Heritage; Federal Constitution; instrument; Guardianship.

\title{
INTRODUÇÃO
}

O objeto enfocado neste artigo é a análise do instituto jurídico da desapropriação no Direito Brasileiro aplicado para a proteção do patrimônio cultural brasileiro, em virtude de expressa disposição constitucional.

$\mathrm{Na}$ seção 1 deste artigo, abordamos o conceito e os bens constitutivos do patrimônio cultural brasileiro, para melhor compreensão do escopo de aplicação do instituto jurídico da desapropriação; na seção 2, a apreciação do instituto jurídico da desapropriação em âmbito constitucional e infraconstitucional: conceito, hipóteses de aplicação e os seus efeitos jurídicos; e na seção 3, as possibilidades de aplicação da desapropriação para a proteção dos bens constitutivos do patrimônio cultural brasileiro.

O objetivo é a sistematização do tema (a desapropriação dos bens culturais) para melhor compreensão da sua aplicabilidade pela sociedade e pelo Poder Público e para a sua análise no âmbito jurídico.

Destacam-se os pressupostos de análise neste artigo que partem da concepção de patrimônio cultural e as realizações significativas do ser humano em seu habitat e bens ambientais de ordem natural, seja tido como espécie do gênero 
SILVA, Fernando Fernandes da; SARTORI, Marcelo Vanzella. A desapropriação e a proteção dos bens culturais no Direito Brasileiro. Revista Eletrônica Direito e Política, Programa de PósGraduação Stricto Sensu em Ciência Jurídica da UNIVALI, Itajaí, v.10, n.1, edição especial de 2015. Disponível em: www.univali.br/direitoepolitica - ISSN 1980-7791.

meio ambiente, merecendo o olhar sobre as referências constitucionais e infraconstitucionais da desapropriação como meio de tutela de referidos bens.

\section{O Patrimônio Cultural Brasileiro e as Medidas de Proteção}

O conceito e os elementos constitutivos do patrimônio cultural brasileiro sob o âmbito jurídico estão definidos no artigo 216 da Constituição Federal de 1988. Da leitura daquele dispositivo verifica-se que o patrimônio cultural brasileiro é constituído pelo conjunto dos bens materiais e imateriais, móveis e imóveis, que contribuíram e contribuem para a "referência, à identidade, à ação, à memória dos diferentes grupos formadores da sociedade brasileira. (...)"

Como ensina José Afonso da Silva: "Tais bens se convertem em bens jurídicos na medida em que são objeto de tutela jurídica, precisamente para a preservação de sua qualificação de bens destinados a satisfazer o interesse da cultura nacional." 3

Em relação ao conceito de patrimônio cultural, observa-se que o constituinte adotou duas técnicas legislativas que possibilitam a sua conceituação: uma de caráter dinâmico, ou seja, quaisquer bens culturais que independentemente da sua natureza, período da sua concepção e localização geográfica, desde que tenham contribuído (passado) ou que contribuam (presente e futuro) para a formação dos "diferentes grupos da sociedade brasileira", são considerados como tais.

Oportuna a lição de Inês Virgínia Prado Soares

O termo patrimônio cultural abriga todos os bens que tenham ou possam ter valor e interesse histórico, artístico, científico ou técnico para a sociedade brasileira como um todo ou para as comunidades de uma região, de um Estado federativo ou de um Município. Assim, o tratamento jurídico do patrimônio cultural deve abrigar, segundo a Constituição, um entendimento aberto e contemporâneo, dentro da

\footnotetext{
${ }^{3}$ SILVA José Afonso da. Ordenação Constitucional da Cultura. São Paulo: Malheiros Editores, 2001, p. 153.
} 
SILVA, Fernando Fernandes da; SARTORI, Marcelo Vanzella. A desapropriação e a proteção dos bens culturais no Direito Brasileiro. Revista Eletrônica Direito e Política, Programa de PósGraduação Stricto Sensu em Ciência Jurídica da UNIVALI, Itajaí, v.10, n.1, edição especial de 2015. Disponível em: www.univali.br/direitoepolitica - ISSN 1980-7791.

diversidade sociocultural do nosso país e da dinâmica em que as relações sociais, econômicas, políticas e culturais se desenvolvem. ${ }^{4}$

A outra técnica legislativa é de caráter objetivo, que compreende os bens culturais em espécie, ou seja, na Constituição há a enumeração de determinados bens que integram o patrimônio cultural brasileiro, a exemplo de determinados conjuntos urbanos.

No artigo 216 da Constituição Federal de 1988 constam os institutos de proteção do patrimônio cultural brasileiro: inventários, registros, vigilância, tombamento, desapropriação "e outras formas de acautelamento e preservação." Em decorrência desta expressão final do próprio texto constitucional admite-se a aplicação de institutos de naturezas diversas, embora não expressos no artigo 216 (jurídicos, administrativos, científicos e técnicos), pois as atividades de proteção são também diversas e possuem uma interdisciplinaridade com diversos ramos do conhecimento. São os casos da aplicação de conhecimentos científicos e técnicos diversos, relativos à conservação e restauração de estátuas, edificações e casas; aqueles relativos à filmografia e a gravação para a proteção e o registro dos bens imateriais; e aqueles relativos ao acondicionamento e o transporte dos bens, etc.

Portanto, a proteção engloba todas as medidas relativas às diversas áreas do conhecimento que objetivam a conservação do bem; e a restrição e até a proibição do seu uso e da sua comercialização para evitar a sua depreciação e até a sua destruição, a exemplo das medidas de restauração que objetivam conservar os aspectos e os elementos originais do bem e prolongar a sua vida.

Nesta perspectiva, o tombamento, no Direito Brasileiro, é o instituto jurídico tradicionalmente aplicado à conservação do bem cultural, pois proíbe o proprietário de mutilar e conseqüentemente destruir o bem tombado, assim como, o obriga a requerer a autorização do Poder Público para reformá-lo, a fim de verificar se as atividades de reforma estão adequadas à manutenção da sua

\footnotetext{
${ }^{4}$ SOARES, Inês Virgínia Prado. Direito ao (do) Patrimônio Cultural Brasileiro. Belo Horizonte: Editora Fórum, 2009, p. 111.
} 
SILVA, Fernando Fernandes da; SARTORI, Marcelo Vanzella. A desapropriação e a proteção dos bens culturais no Direito Brasileiro. Revista Eletrônica Direito e Política, Programa de PósGraduação Stricto Sensu em Ciência Jurídica da UNIVALI, Itajaí, v.10, n.1, edição especial de 2015. Disponível em: www.univali.br/direitoepolitica - ISSN 1980-7791.

conservação. Entretanto, a desapropriação pode ser aplicada como uma medida alternativa ao tombamento justamente para reforçar os aspectos de proteção do primeiro.

\section{A DESAPROPRIAÇÃO NO DIREITO BRASILEIRO}

O Poder Público, por meio do instituto da desapropriação, com fundamento na Constituição e na legislação infraconstitucional, adquire compulsoriamente do particular ou de outro ente público o direito de propriedade sobre determinado bem, passando este direito a incorporar o patrimônio do ente público expropriante, como forma de aquisição originária de propriedade. É o pensamento de Celso Antônio Bandeira de Mello

Do ponto de vista teórico, pode-se dizer que desapropriação é o procedimento através do qual o Poder Público compulsoriamente despoja alguém de uma propriedade e a adquire, mediante indenização, fundado em um interesse público. Trata-se, portanto, de um sacrifício de direito imposto ao desapropriado. ${ }^{5}$

A desapropriação é o instituto jurídico que possui fundamento no princípio da supremacia do interesse público sobre o privado que confere ao Poder Público a legitimidade para praticar ações em prol do interesse público e coletivo em primazia ao privado. Trata-se do reconhecimento do Estado como instituição tutora do interesse público e coletivo competindo a ele, mediante os seus agentes e órgãos, identificá-lo e protegê-lo ao promover as suas políticas públicas

O propósito público, ou interesse público, é conceito multifacetado. Por não ser facilmente identificado ou delimitado, não é conceito finito e objetivo. Deve-se compreender o conceito, portanto, em direito administrativo, por meio de uma ponderação dos interesses envolvidos em cada caso concreto. Em busca de uma compreensão da

\footnotetext{
${ }^{5}$ MELLO, Celso Antônio Bandeira de. Curso de Direito Administrativo. 26a edição. São Paulo: Malheiros Editores, 2008, p. 858.
} 
SILVA, Fernando Fernandes da; SARTORI, Marcelo Vanzella. A desapropriação e a proteção dos bens culturais no Direito Brasileiro. Revista Eletrônica Direito e Política, Programa de PósGraduação Stricto Sensu em Ciência Jurídica da UNIVALI, Itajaí, v.10, n.1, edição especial de 2015. Disponível em: www.univali.br/direitoepolitica - ISSN 1980-7791.

função social da propriedade devem-se considerar direitos individuais e metaindividuais. ${ }^{6}$

Na Constituição Federal de 1988 há a previsão de diversas modalidades de desapropriação, em face de motivações e propósitos distintos, observando-se que a transferência compulsória da propriedade é o denominador comum que permeia todas as modalidades.

Um exemplo significativo é a desapropriação em prol da política agrícola e fundiária e da reforma agrária, com fundamento nos seus artigos 184 e 185; outro exemplo é a previsão constitucional da desapropriação em decorrência de atos ilícitos penais: uma modalidade de desapropriação-sanção. Consta no seu artigo 243 que as "glebas de qualquer região do País" onde se praticam "culturas ilegais de plantas psicotrópicas" devem ser imediatamente "expropriadas" e destinadas ao assentamento de colonos, sem qualquer obrigação de indenizar o proprietário, que poderá sofrer outras sanções previstas no nosso ordenamento jurídico.

\section{A DESAPROPRIAÇÃO COMO INSTITUTO DE PROTEÇÃO DO PATRIMÔNIO CULTURAL BRASILEIRO}

Como já comentado, a desapropriação é um dos institutos jurídicos de proteção do patrimônio cultural brasileiro previsto no artigo 216 da Constituição Federal de 1988. Cabe-nos nesta seção identificar no ordenamento jurídico as modalidades de desapropriação que se integram à norma constitucional sobre o tema.

6 FARIA, Márcia. O Direito Urbanístico e o Direito de Propriedade Norte-Americanos: Planejamento Urbano e Desapropriação para Fins de Interesse Público após a Decisão do Caso Kelo vs. City of New London. Direito Público. Ano IV, número 14, outubro-novembro de 2006, p. 41. 
SILVA, Fernando Fernandes da; SARTORI, Marcelo Vanzella. A desapropriação e a proteção dos bens culturais no Direito Brasileiro. Revista Eletrônica Direito e Política, Programa de PósGraduação Stricto Sensu em Ciência Jurídica da UNIVALI, Itajaí, v.10, n.1, edição especial de 2015. Disponível em: www.univali.br/direitoepolitica - ISSN 1980-7791.

\subsection{A desapropriação por utilidade pública ou interesse social}

A Constituição Federal de 1988 possui uma norma geral sobre desapropriação que atende à tradição do Direito Brasileiro de reconhecer a competência do Poder Público de desapropriar bens dos entes privados ou de outros entes públicos, com fundamento nas hipóteses de utilidade pública ou interesse social:

"a lei estabelecerá o procedimento para desapropriação por necessidade ou utilidade pública, ou por interesse social, mediante justa e prévia indenização em dinheiro, ressalvados os casos previstos nesta Constituição." ${ }^{77}$

Este é o fundamento que confere validade e vigência ao Decreto-Lei número 3.365/41, que contém as hipóteses de desapropriação por utilidade pública; e à lei 4.132/62 que regula as hipóteses de desapropriação por interesse social. Em suma, ambas as fontes jurídicas foram recepcionadas pela Constituição atual e dispõem sobre normas de proteção do patrimônio cultural brasileiro.

Em atendimento ao princípio da legalidade na seara da Administração Pública ${ }^{8}$, a modalidade de desapropriação, tratada nesta seção, somente poderá ocorrer se fundada numa das hipóteses discriminadas nos diplomas legais citados, que se diferenciam em face de dois aspectos: a) as hipóteses de utilidade pública e de interesse social são distintas; b) o prazo de caducidade para declaração de desapropriação por utilidade pública é de cinco anos; o prazo de caducidade para declaração da desapropriação para fins de interesse social é de dois anos.

No que diz respeito ao Decreto-Lei número 3.365/41, que contém as hipóteses de utilidade pública, destacamos aquelas pertinentes à proteção do patrimônio cultural: "a preservação e conservação dos monumentos históricos e artísticos, isolados ou integrados em conjuntos urbanos ou rurais, bem como medidas necessárias a manter-Ihes e realçar-Ihes os aspectos mais valiosos ou característicos e, ainda, a proteção de paisagens e locais particularmente dotados pela natureza;" "a preservação e a conservação adequada de arquivos,

\footnotetext{
${ }^{7}$ Cf. art. 50, inciso XXIV, da Constituição Federal de 1988.

${ }^{8}$ Cf. art. 37, caput, da Constituição Federal de 1988.

${ }^{9}$ Cf. art. 50, alínea "k", do Decreto-Lei no 3.365/41.
} 
SILVA, Fernando Fernandes da; SARTORI, Marcelo Vanzella. A desapropriação e a proteção dos bens culturais no Direito Brasileiro. Revista Eletrônica Direito e Política, Programa de PósGraduação Stricto Sensu em Ciência Jurídica da UNIVALI, Itajaí, v.10, n.1, edição especial de 2015. Disponível em: www.univali.br/direitoepolitica - ISSN 1980-7791.

documentos e outros bens móveis de valor histórico ou artístico;"10 e "a construção de edifícios públicos, monumentos comemorativos e cemitérios."11 Além dessas hipóteses, a lei 3924/61, prevê a desapropriação por utilidade pública para os bens arqueológicos:

"Art. 15. Em casos especiais e em face do significado arqueológico excepcional das jazidas, poderá ser promovida a desapropriação do imóvel, ou parte dele, por utilidade pública, com fundamento no art. 50, alíneas "k" e "L" do Decreto-lei 3.365, de 21.06.1941."

Na lei 4.132/62, que regula as hipóteses de desapropriação por interesse social, a regra pertinente ao patrimônio cultural é a seguinte: "a utilização de áreas, locais ou bens que, por suas características, sejam apropriados ao desenvolvimento de atividades turísticas" ${ }^{12}$; o que possibilita a desapropriação sobre bens culturais que dadas as suas características devem ser incorporados ao patrimônio cultural brasileiro e se destinam ao turismo de âmbito nacional e internacional.

Em ambas as hipóteses legais, o expropriado possui o direito à justa indenização em dinheiro.

\subsection{A desapropriação pelo valor cultural}

Trata-se da modalidade de desapropriação prevista no artigo 216, instituída para outorgar ao Poder Público a competência para desapropriar um bem, ao constatar mediante a provocação dos seus órgãos de proteção, o seu valor cultural.

Portanto, o instituto da desapropriação por utilidade pública ou interesse social, previsto nos Decreto-Lei número 3.365/41 e Decreto-Lei 4.132/62, continua a ser aplicado na proteção dos bens culturais. Entretanto, interpretamos que as

\footnotetext{
${ }^{10}$ Cf. art. 50, alínea "I", do Decreto-Lei no 3.365/41.

${ }^{11}$ Cf. art. 50, alínea "m", do Decreto-Lei no 3.365/41.

12 Cf. art. 20, inciso VIII, incluído pela Lei no 6.513/77.
} 
SILVA, Fernando Fernandes da; SARTORI, Marcelo Vanzella. A desapropriação e a proteção dos bens culturais no Direito Brasileiro. Revista Eletrônica Direito e Política, Programa de PósGraduação Stricto Sensu em Ciência Jurídica da UNIVALI, Itajaí, v.10, n.1, edição especial de 2015. Disponível em: www.univali.br/direitoepolitica - ISSN 1980-7791.

disposições legais referentes à proteção daqueles bens não foram recepcionadas pela Constituição Federal de 1988, pelo fato de que o conceito de patrimônio cultural e os seus bens constitutivos e característicos são mais amplos que o previsto nas constituições de 1937, de 1945, e de 1967, que deram fundamentos àqueles diplomas legais.

Em suma, os decretos-leis continuam em vigor nos aspectos procedimentais e nas hipóteses cabíveis, à exceção daqueles relativos aos bens culturais, que dão lugar ao conceito previsto na Constituição Federal de 1988. Assim, a aplicação da desapropriação adquire uma dimensão mais ampla em relação ao escopo de proteção. Esta interpretação, também, nos permite a aplicação do instituto jurídico da desapropriação, em duas situações consideradas tradicionais no Direito Brasileiro. Vejamos.

\subsubsection{A desapropriação e o tombamento prévio}

A norma constitucional do artigo 216 da Constituição Federal nos remete à regra do artigo 19 do Decreto-Lei no 25/37 que outorga a competência para o Poder Público promover a desapropriação sobre o bem já tombado, nas hipóteses em que o proprietário não dispuser de recursos financeiros para a realização de obras ou serviços para a conservação do bem:

Art. 19. O proprietário da coisa tombada, que não dispuser de recursos para proceder às obras de conservação e reparação que a mesma requerer, levará ao conhecimento do Instituto do Patrimônio Histórico e Artístico Nacional, a necessidade das mencionadas obras, sob pena de multa correspondente ao dobro da importância em que for avaliado o dano sofrido pela mesma coisa.

Parágrafo primeiro - Recebida a comunicação e consideradas necessárias as obras, o diretor do Instituto do Patrimônio Histórico e Artístico Nacional mandará executá-las, a expensas da União, devendo as mesmas ser iniciadas dentro do prazo de seis meses, ou providenciará para que seja feita a desapropriação da coisa. 
SILVA, Fernando Fernandes da; SARTORI, Marcelo Vanzella. A desapropriação e a proteção dos bens culturais no Direito Brasileiro. Revista Eletrônica Direito e Política, Programa de PósGraduação Stricto Sensu em Ciência Jurídica da UNIVALI, Itajaí, v.10, n.1, edição especial de 2015. Disponível em: www.univali.br/direitoepolitica - ISSN 1980-7791.

Conforme a regra, trazida à colação, o seu objetivo é claro: a desapropriação como instrumento subsidiário do tombamento para a proteção do bem cultural. A referida norma foi recepcionada pela Constituição Federal de 1988, no seu aspecto material, qual seja, a motivação é a tutela do valor cultural do bem. A desapropriação se apresenta como uma opção do Poder Público ao constatar que o tombamento não é a medida suficiente de proteção, como leciona Maria Coeli Simões Pires

Por óbvio, condição sine qua non para que se fundamente a desapropriação com os pressupostos do art. 19 é a existência do tombamento, o que não equivale a dizer que os bens tombados só se submetem à desapropriação em situações que tais. É que, reconhecida a insuficiência de condições do proprietário para a preservação do bem, a desapropriação se coloca como obrigação alternativa do Poder Público, como forma de garantia da permanência do regime de proteção. ${ }^{13}$

\subsubsection{A desapropriação e o tombamento oneroso}

Ainda em decorrência do artigo 216 da Constituição Federal de 1988, outra modalidade de desapropriação de bens culturais pode ser considerada recepcionada. Trata-se da relação entre o tombamento compulsório e o esvaziamento econômico do bem: o Poder Público ao tombar compulsoriamente o bem cultural constata a inviabilidade do seu aproveitamento econômico pelo proprietário utilizando-se da desapropriação como meio de indenizá-lo, como salientam os doutrinadores Carlos Medeiros Silva: "O tombamento oneroso exige a desapropriação com o pagamento da justa indenização em dinheiro"14; e José Afonso da Silva

É claro que se, numa situação concreta, o tombamento aniquilar totalmente o valor econômico da propriedade, com

\footnotetext{
13 PIRES, Maria Coeli Simões. Da Proteção ao Patrimônio Cultural. Belo Horizonte: Del Rey Editora, 1994, p. 250.

14 SILVA, Carlos Medeiros. Patrimônio Histórico e Artístico Nacional - Tombamento Notificação do Proprietário - Registro - Nulidade (Parecer) Revista de Direito Administrativo. Rio de Janeiro: Fundação Getúlio Vargas. Volume 120, abril/junho de 1975, p. 459.
} 
SILVA, Fernando Fernandes da; SARTORI, Marcelo Vanzella. A desapropriação e a proteção dos bens culturais no Direito Brasileiro. Revista Eletrônica Direito e Política, Programa de PósGraduação Stricto Sensu em Ciência Jurídica da UNIVALI, Itajaí, v.10, n.1, edição especial de 2015. Disponível em: www.univali.br/direitoepolitica - ISSN 1980-7791.

certeza cabe indenização, mas isso nada tem a ver com a natureza em si do tombamento. ${ }^{15}$

Este posicionamento da Doutrina, no Direito Brasileiro, alcançou o seu amadurecimento no caso sobre o tombamento do Pico do Itabirito (MG), onde se localiza a mina "Cata Branca", cujo proprietário recebeu do Poder Público o direito de lavra, sob a vigência da então Constituição de 1946.

O Poder Público ao declarar o tombamento de todo o Pico do Itabirito impossibilitou as atividades de execução da lavra, porque tais atividades acarretariam ou a sua destruição, ou a sua demolição ou a sua mutilação, atos que caracterizam infração ao art. 17 do Decreto-Lei número 25/37. ${ }^{16}$

Neste sentido, ficou claro que havia uma incompatibilidade entre a obrigação prevista no art. 17 , do Decreto-Lei número 25/37, de proteger todo o pico na sua integridade, e o direito do proprietário e do eventual concessionário de executar a lavra do bem, ou seja, o próprio Pico do Itabirito.

No início dos anos sessenta, do século passado, o jurista Carlos Medeiros Silva sustentou a tese da desapropriação, como alternativa ao tombamento compulsório por gerar "na negação ou restrição total do direito de propriedade"17.

15 SILVA, José Afonso da. Ordenamento Constitucional da Cultura. São Paulo: editora Malheiros, 2001, p. 162.

16 SILVA, Carlos Medeiros. Patrimônio Histórico e Artístico Nacional - Tombamento Desapropriação - Concessão de Lavra - Ato Administrativo - Revogação. (Parecer). p. 248-258.

17 (i) SILVA, Carlos Medeiros. Patrimônio Histórico e Artístico Nacional - Tombamento Desapropriação - Concessão de Lavra - Ato Administrativo - Revogação. (Parecer), p. 248.

(ii) Ainda conforme, o próprio jurista relatou: "Em conclusão, como procurei demonstrar, o tombamento, relatado na consulta, é nulo porque impossibilita a lavra do maciço, assegurada por ato administrativo válido e eficaz, criador de direitos individuais, irrevogável por motivo de conveniência, reconhecida posteriormente; somente a desapropriação, com indenização prévia e justa em dinheiro, poderá extinguir os direitos patrimoniais decorrentes da situação jurídica constituída na forma da Lei de Minas, salvo infração desta, de que se não cogita." Cf. Carlos Medeiros Silva. "Patrimônio Histórico e Artístico Nacional - Tombamento - Desapropriação Concessão de Lavra - Ato Administrativo - Revogação. (Parecer)." Revista de Direito Administrativo. Rio de Janeiro: Editora da Fundação Getúlio Vargas, volume 67, janeiro-março de 1962, p. 257. 
SILVA, Fernando Fernandes da; SARTORI, Marcelo Vanzella. A desapropriação e a proteção dos bens culturais no Direito Brasileiro. Revista Eletrônica Direito e Política, Programa de PósGraduação Stricto Sensu em Ciência Jurídica da UNIVALI, Itajaí, v.10, n.1, edição especial de 2015. Disponível em: www.univali.br/direitoepolitica - ISSN 1980-7791.

Esta interpretação nos parece mais adequada, pois não se trata necessariamente de "esvaziamento econômico do bem", e sim a perda, pelo titular do direito de propriedade, de exercer o direito de uso, de gozo ou de fruição de forma plena. Dependendo da medida de proteção, o titular do direito de propriedade poderá ser proibido de determinados atos: uma casa tombada não poderá ser destruída para dar lugar a um estacionamento. Conforme o referido exemplo, o aproveitamento econômico pelo proprietário não poderá ser pleno se comparado a outros proprietários em condições similares; porém, a situação jurídica criada pelo tombamento não retira totalmente o valor econômico da casa que se mantém por razões diversas: uma delas pelo fato de possuir um valor cultural que pode ser a base para a instituição de um museu ou de local de exposições de obras artísticas.

\subsection{A desapropriação e a política urbana}

A Constituição Federal de 1988 prevê que a política de desenvolvimento urbano executada pelo Poder Público deve obedecer às "diretrizes gerais fixadas em lei" e objetivar o "pleno desenvolvimento das funções sociais da cidade e garantir o bem-estar de seus habitantes." ${ }^{18}$

A lei 10.257/2001, conhecida comumente por Estatuto da Cidade, regula as diretrizes gerais da política urbana aludida pela norma constitucional, entre elas a observância da proteção, da preservação e da recuperação do "meio ambiente natural e construído, do patrimônio cultural, histórico, artístico, paisagístico e arqueológico"19, classificando a desapropriação como um dos instrumentos políticos e jurídicos de execução da política urbana. ${ }^{20}$

(iii) A Doutrina sustenta a tese da aplicação do artigo 50, alíneas "k" e "I", do Decreto-Lei 3.365/41, como fundamento da desapropriação sobre bens culturais em tais condições.

${ }^{18}$ Cf. artigo 182, "caput", da Constituição Federal de 1988.

19 Cf. art. 20, inciso XII, da Lei no 10.257/2001.

${ }^{20}$ Cf. art. 182, parágrafo terceiro, da Constituição Federal de 1988 e art. 40, inciso V, alínea "a", da Lei no $10.257 / 2001$. 
SILVA, Fernando Fernandes da; SARTORI, Marcelo Vanzella. A desapropriação e a proteção dos bens culturais no Direito Brasileiro. Revista Eletrônica Direito e Política, Programa de PósGraduação Stricto Sensu em Ciência Jurídica da UNIVALI, Itajaí, v.10, n.1, edição especial de 2015. Disponível em: www.univali.br/direitoepolitica - ISSN 1980-7791.

\section{CONSIDERAÇÕES FINAIS}

A Constituição Federal de 1988, no seu artigo 216, prevê a desapropriação como um dos institutos jurídicos de proteção do patrimônio cultural brasileiro. Em virtude de outras normas constitucionais que prevêem a desapropriação, como a legislação vigente sobre a matéria, podemos concluir o seguinte:

a) A desapropriação é o instituto jurídico previsto no ordenamento jurídico brasileiro que se caracteriza pela transferência forçada da propriedade do ente particular e de outros entes públicos para o Poder Público, mediante, geralmente, por justa e prévia indenização em dinheiro;

b) A desapropriação prevista no artigo 216 da Constituição Federal de 1988 enquadra-se na definição estabelecida na alínea "a", cuja finalidade é a proteção dos bens que possuem valor cultural, conforme os critérios previstos naquela norma constitucional;

c) Consequentemente, a desapropriação para a proteção dos bens culturais pode ser direta, pela constatação do valor cultural do bem que motiva o Poder Público a desapropriá-lo; pode ser subsidiária ao tombamento, conforme a hipótese do artigo 19 do Decreto-Lei no 25/37, ou seja, nos casos em que o proprietário não possui condições financeiras para arcar com as despesas da conservação; e como alternativa ao tombamento oneroso, nas hipóteses em que sua extensão aniquila o pleno exercício do direito de propriedade pelo seu titular;

d) E, finalmente, a desapropriação como instrumento de promoção da política urbana, aplicada aos bens culturais urbanos, com diversos propósitos, entre eles a promoção da revitalização de centros históricos pelo Poder Público, para a melhoria da qualidade de vida da população.

\section{REFERÊNCIAS DAS FONTES CITADAS}

FARIA, Márcia. O Direito Urbanístico e o Direito de Propriedade NorteAmericanos: Planejamento Urbano e Desapropriação para Fins de 
SILVA, Fernando Fernandes da; SARTORI, Marcelo Vanzella. A desapropriação e a proteção dos bens culturais no Direito Brasileiro. Revista Eletrônica Direito e Política, Programa de PósGraduação Stricto Sensu em Ciência Jurídica da UNIVALI, Itajaí, v.10, n.1, edição especial de 2015. Disponível em: www.univali.br/direitoepolitica - ISSN 1980-7791.

Interesse Público Após a Decisão do Caso Kelo vs. City of New London. Direito Público. Ano IV, número 14, outubro-novembro de 2006;

MELLO, Celso Antônio Bandeira de. Curso de Direito Administrativo. 26a edição. São Paulo: Malheiros Editores, 2008;

PIRES, Maria Coeli Simões. Da Proteção ao Patrimônio Cultural. Belo Horizonte: Del Rey, 1994;

SILVA, Carlos Medeiros. Patrimônio Histórico e Artístico Nacional Tombamento - Desapropriação - Concessão de Lavra - Ato Administrativo - Revogação. (Parecer). Revista de Direito Administrativo. Rio de Janeiro: Fundação Getúlio Vargas. Volume 120, abril/junho de 1975, pp. 248258;

Patrimônio Histórico e Artístico Nacional - Tombamento Notificação do Proprietário - Registro - Nulidade (Parecer). Revista de Direito Administrativo. Rio de Janeiro: Fundação Getúlio Vargas. Volume 120, abril/junho de 1975, pp. 459-469;

SILVA, José Afonso da. Ordenação Constitucional da Cultura. São Paulo: Malheiros Editores, 2001;

SOARES, Inês Virgínia Prado. Direito ao (do) Patrimônio Cultural Brasileiro. Belo Horizonte: Editora Fórum, 2009.

Submetido em: Outubro/2014

Aprovado em: Outubro/2014 